\title{
The Impact of Cultural Globalisation on Identity Formation among the Malaysian Chinese
}

\author{
Rachel Chan Suet Kay
}

\section{Doi:10.5901/ajis.2013.v2n9p475}

\begin{abstract}
Globalisation has been a widely contested concept, a term bandied about since the 1980s. In general it implies a breaking down of boundaries of time and space. Supporters of globalisation separate their analysis of the effects of globalisation into three major dimensions - economic, political, and cultural. The focus of this paper is on the latter - the cultural. The impact of cultural globalisation on the socialisation process which forms social identity for individuals is of interest. A major concern is whether globalisation has led to cultural homogenisation or cultural differentiation. The author hence attempts to answer this question with the case study of the Malaysian Chinese, who have historically been divided into two main groups - the Chineseeducated, and the non-Chinese educated, diverging in terms of values, aspirations, and lifestyles. Was there a division of cultural capital among Chinese-educated and non-Chinese educated Malaysian Chinese, prior to globalisation? After globalisation (circa 1980s), did these differences still remain? Did the two main groups become homogenised instead? Or hybridised? Does this prove or reject the hyperglobalist point of view that there is cultural homogenisation, and if it is proved, is it free-market driven? What are its mechanisms, in terms of the process of socialisation? A survey questionnaire was distributed to 200 respondents from three institutions of higher education in Malaysia, centering in the capital city - the locus of globalising activity. Three institutions were selected for their representativeness of the two Malaysian Chinese groups, and one was selected as a control group, containing a mixture of both. The results show that respondents are aware of the impact of globalisation and that certain attitudes and practices have been altered as compared to historical trends, as a result.
\end{abstract}

\section{Introduction}

1. This paper takes the starting point of globalisation and examines its impact on identity formation among the Malaysian Chinese. Globalisation, albeit a contested concept since the 1980s, has been said to contain three dimensions within its completion. These are the economic, political, and cultural dimensions. In general, globalisation is the breaking down of boundaries of time and space (Waters, 2001). Marxist theorist Leslie Sklair argues that there is a transnational capitalist class which is now representing the global bourgeoisie. This class, hereby known as the TCC, controls the flows of economic capital worldwide and are made up of executives, politicians, state officials, and the mass media. Together, they spread the consumerist propaganda known as the 'culture-ideology of consumerism' (Sklair, 2002).

2. One offshoot of this ideology is the remaking of identities to suit consumption tastes. This occurs in tandem with the tenets of neoliberalism. Supporters of globalisation laud its neoliberal benefits, citing a promise of greater homogenisation in economic, political, and cultural practices across the globe. The merging of identities into one that is largely dictated by the free market is hailed as a desirable end. This has consequences for the formation of cultural identities within nation-states. Of particular interest is the effect on identity formation among the Malaysian Chinese.

3. This paper takes the line of argument regarding Bourdieu's cultural capital, and how possession of it is changing hands within this new climate. Bourdieu originally posited cultural capital as a measure of a set of knowledge, norms, values, beliefs, and lifestyle practices that were unique to social groups mostly based on economic class (Bourdieu, 1986). However it is different from economic capital in the sense that it is not purely quantitative and not related to the means of production in the Marxian sense. Rather, these were superstructural attributes ideas that members of a certain social class might subscribe to. However, this would then raise the question of whether the concept of social class is still relevant today. Recent evidence, in the case of the 2013 BBC-LSE British Social Class Survey indicates otherwise (Savage et. al, 2013).

4. With that said, I shall move away from the use of the concept of social class. I will acknowledge instead that social class, as measured originally by Marx as a person's relation to the means of production, is not my measure of identity here, but cultural capital is instead. Thus, this paper uses Bourdieu's notion of cultural capital 
to argue that Malaysian Chinese groups' possession of cultural capital is changing as an impact of cultural globalisation.

5. To say this, we must begin from the origins of Malaysian Chinese groups as mentioned earlier. Malaysian Chinese immigrants first arrived in Malaya as workers from China. Around the 1900s, the first Chinese schools were founded - one of them being the landmark Chinese school, Chung Hwa Independent High School which still exists strongly today. These schools based their education syllabi on textbooks from China, which at that time contained strong nationalist sentiments. This led the Malaysian Chinese pupils to develop a strong loyalty to China. At the same time, the British who were occupying Malaya introduced their own school system - based in the medium of English language as well as having its own rational, Enlightenment-influenced syllabus as opposed to China's Confucian-influenced syllabus. The goal was to train a local officer class to serve the British in Malaya. The Chinese educated Chinese did not appreciate this orientation due to its focus on science over moral and civic education. The only reason the Chinese syllabus introduced science-based subjects was due to China's intent to keep up with the West, technologically (Purcell, 1948).

6. Hence, this gave rise to a division in mindsets, lifestyles, and aspirations - with the Chinese-educated Malaysian Chinese loyal to their 'imagined community' which was China; and the English-educated Malaysian Chinese keen for the establishment of roots in a multicultural Malayan nation-state. This continued into more battles for the rights to uphold Chinese education in Malaysia even after it achieved independence from the British - till now. But slowly, the lines of the division are waning and recent trends demonstrate a meshing between the two. There is now a greater intent among the non-Chinese educated (as of today these include not only English schools but also Malay schools) to immerse themselves in the history and language of their Chinese ancestors. At the same time, due to the demands of globally competitive education, many Chinese-educated youngsters are being sent to English-medium institutions of tertiary education. Thereby lies the desire to embrace both sides of the spectrum. Rita Sim who has recently published a book based on her analysis of media consumption among the Malaysian Chinese also posits a new hybrid - a third group of Malaysian Chinese who are a result of this cultural capital crossover (Sim, 2011).

7. In this paper, I highlight results from a pre-test conducted among youth from Generation $Y$ - the current generation who are the most influential in terms of setting trends in education, work, and even voting in Malaysia.

\section{Data}

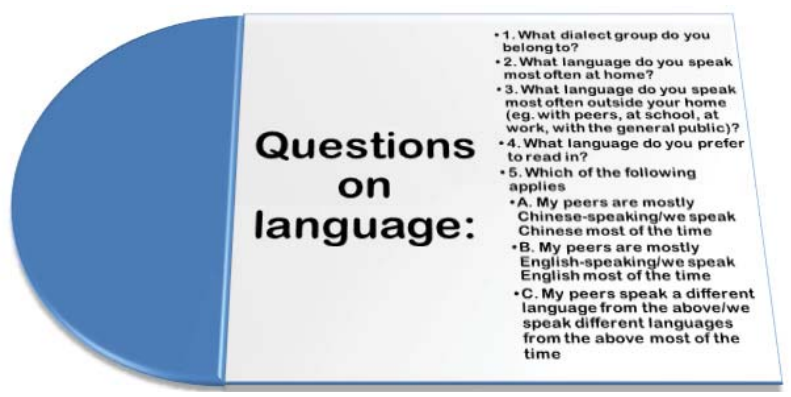

Figure 1: A selection of questions from my cultural capital questionnaire with regards to language used by respondents.

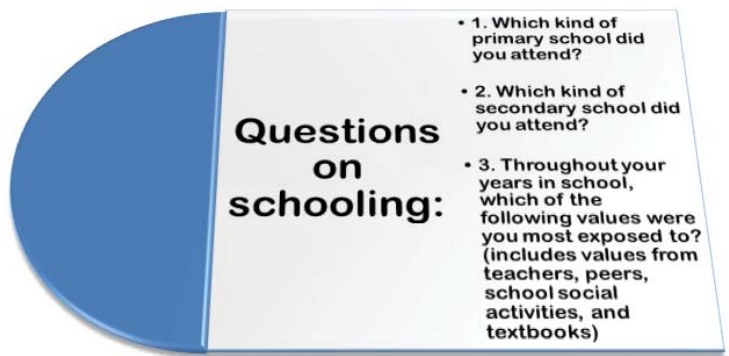

Figure 2: A selection of questions from my cultural capital questionnaire with regards to primary and secondary schooling of respondents. 


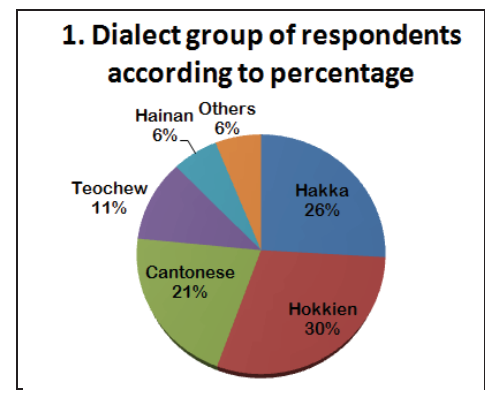

Figure 3: Dialect group of respondents according to percentage.

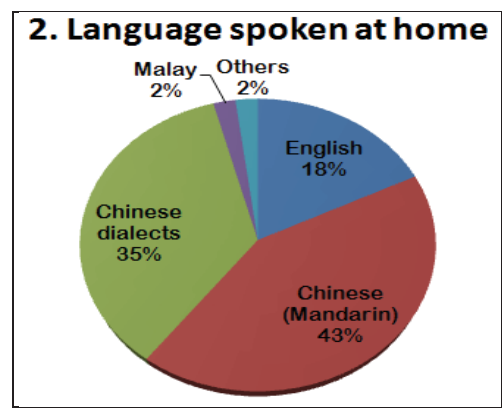

Figure 4: Language spoken by respondents at home.

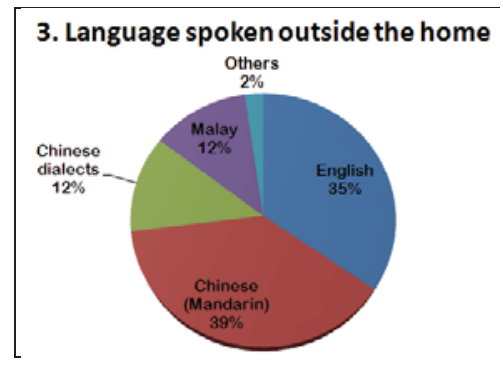

Figure 5: Language spoken by respondents outside the home.

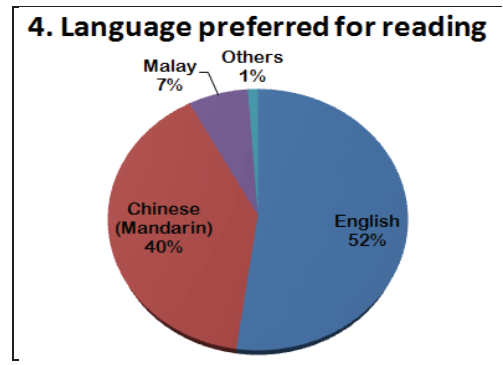

Figure 6: Language preferred by respondents for reading in. 


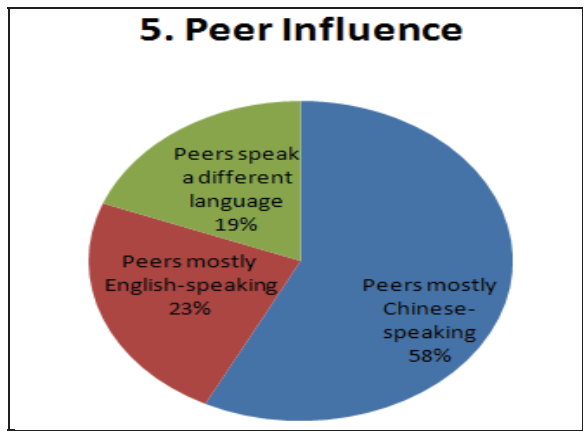

Figure 7: Language most commonly used according to respondents' peer groups.

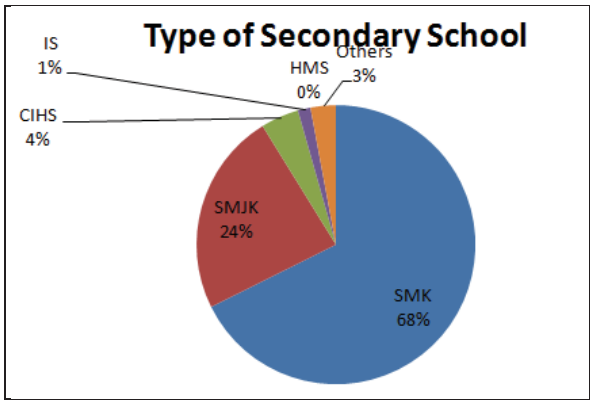

Figure 8: Type of secondary school attended by respondents

[IS - International school, CIHS - Chinese Independent High School, HMS- Homeschooled, SMK - State Secondary School (Malay medium), SMJK - State Secondary School (Chinese medium)]

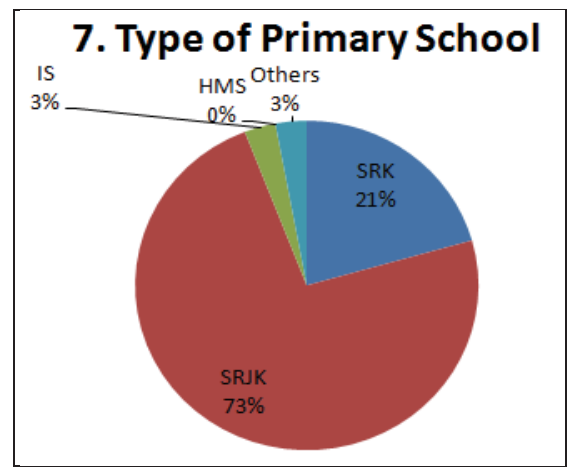

Figure 9: Type of primary school attended by respondents

[IS - International school, HMS- Homeschooled, SRK - State Primary School (Malay medium), SRJK - State Primary School (Chinese medium)] 


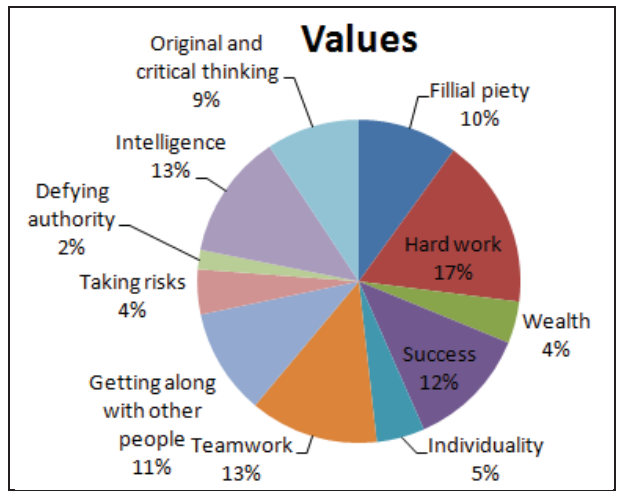

Figure 10: Values transmitted through primary and secondary education

\section{Comparison to Historical-Based Identities}

\begin{tabular}{|c|c|c|}
\hline Type of Chinese & Language & Description \\
\hline A & $\begin{array}{l}\text { Speak at least a Chinese language and } \\
\text { are literate in Chinese. LOI is usually a } \\
\text { Chinese language. LOL is Chinese, and } \\
\text { possibly other languages too. Preferred } \\
\text { IGL is Chinese (Mandarin on other } \\
\text { Chinese languages). }\end{array}$ & $\begin{array}{l}\text { Because of common literacy in Chinese, } \\
\text { Type A Chinese everywhere share certain } \\
\text { similar interests in Chinese language, } \\
\text { Chinese literature and Chinese arts. They } \\
\text { generally have more knowledge and } \\
\text { interest in Chinese history, philosophy, and } \\
\text { civilisation than other categories of } \\
\text { Chinese. }\end{array}$ \\
\hline B & $\begin{array}{l}\text { Speak at least a Chinese language, but do } \\
\text { not read and write Chinese. LOI is usually } \\
\text { a Chinese language. LOL (if any) is non- } \\
\text { Chinese. Preferred IGL is usually Chinese } \\
\text { and/or non-Chinese. }\end{array}$ & $\begin{array}{l}\text { These include (a) Chinese who are illiterate } \\
\text { but can speak at least one Chinese } \\
\text { language and (b) Chinese who can speak a } \\
\text { Chinese language but for whom the } \\
\text { language of literacy is not Chinese. }\end{array}$ \\
\hline
\end{tabular}

\begin{tabular}{|c|c|c|}
\hline Type of Chinese & Langunge & Description \\
\hline c & $\begin{array}{l}\text { Do not speak any Chinese language nor } \\
\text { write Chinese. LOI is non-Chinese. LOL (if } \\
\text { any) is non-Chinese. Preferred IGL is the } \\
\text { same as LOI and LOL. } \\
\text { (Note: } \\
\text { LOE:Language of intimacy } \\
\text { LOL-Language of Literacy } \\
\text { IGL: Intra-Group Language } \\
\text { From Tan Chee-Beng's Chinese Overseas, } \\
\text { Pp. } 129 .]\end{array}$ & $\begin{array}{l}\text { These are 'acculturated' Chinese. The } \\
\text { Baba of Melaka are a good example. They } \\
\text { speak one or more non-Chinese languages } \\
\text { (Baba Malay and English in the case of the } \\
\text { Baba), and if literate, the language of } \\
\text { literacy is also not Chinese (English and/or } \\
\text { Malay in the case of the Baba). }\end{array}$ \\
\hline D & $\begin{array}{l}\text { LOI is a localised Chinese language and } \\
\text { one or more non-Chinese languages. LOL } \\
\text { (if any) is usually non-Chinese. Preferred } \\
\text { IGL is the same as the LOI. }\end{array}$ & $\begin{array}{l}\text { These are also acculturated Chinese but } \\
\text { unlike Type C, theystill speak an } \\
\text { acculturated Chinese language. An } \\
\text { example would be the Peranakan-type } \\
\text { Chinese in Northeast Kelantan, who speak } \\
\text { an acculturated version of Hokkien, } \\
\text { Kelantan Malay dialect, many of whom also } \\
\text { speak the local Thai dialect. }\end{array}$ \\
\hline
\end{tabular}

Figure 7: Historical types of Malaysian Chinese according to spoken and written language (Tan 2007) 


\section{Analysis}

1. From Figure 2, most respondents are from the Hokkien dialect group. 'Ah Beng' is originally a Hokkien phrase.

2. From Figure 3, $43 \%$ speak Mandarin as a 'language of intimacy', $35 \%$ use other Chinese dialects (presumably Hokkien). In total, $78 \%$ of Malaysian Chinese respondents do utilise Chinese language as their 'language of intimacy'.

3. From Figure 4, as for 'language of literacy' the majority use Mandarin and Chinese dialects (39\% use Mandarin, while $12 \%$ use Chinese dialects). English is a close second at $35 \%$.

4. From Figure 4, once again, as for the 'language of literacy' Chinese language comes a close second to English. This indicates that Chinese language is as important as English in the globalised world.

5. From Figure 5, regarding peers as an agent of socialisation, the lifestyle practice of respondents show that their peers are mostly Chinese-speaking, at $58 \%$.

6. With comparison to Tan Chee-Beng's original classification of Malaysian Chinese, it is found that the majority of Malaysian Chinese respondents use Chinese language as their 'language of intimacy' while at the same time using English language as a main 'language of literacy' with Chinese language second.

7. With comparison to my original classification of Malaysian Chinese language-based identities, it is apparent that the importance of Chinese language has been acknowledged by the respondents. 74\% of them attended Chinese-language primary school, while only $24 \%$ attended Chinese-language secondary school. This shows that while parents desire to maintain the transmission of cultural identity, they do recognise the fact that in this globalising world children need to be competent in the dominant lingua franca, which is English.

8. This shows that Malaysian Chinese youth would be socialised to have a background with knowledge of their mother tongue (with at least some basic writing and reading ability) as well as the same capacities in English.

9. There is thus some convergence in tying the most profitable elements of both Chinese-language and nonChinese language education together. Compared to the past, there is a mix and match and parents and children are no longer so caught up in rigid nationalism or ethnocentrism but are aware of the compression of space and time - the major hallmarks of globalisation.

\section{Conclusion}

The results of the survey show that Malaysian Chinese have converged in some areas of identity formation but not in others. While there is a general acceptance of the English language as a language of global importance, the importance of Chinese language has not been eclipsed. This shows that cultural homogenisation among the Malaysian Chinese is occurring, but not as a deterministic totality.

\section{References}

Waters, M. (2001) Globalization 2nd ed. Routledge: Oxford. P5.

Sklair, L. (2002) Democracy and the Transantional Capitalist Class. Available from: <http://www.uni-muenster.de/PeaCon/global-texte/r$\mathrm{m} / 144$ sklair.pdf> [Acceseed on 18 June 2013].

Bourdieu, P (1986). The Forms of Capital. Available from <http://www.marxists.org/reference/subject/philosophy/works/fr/bourdieuforms-capital.htm> [Accessed 18 June 2013].

Savage et al. (2013). 'A New Model of Social Class: Findings from the BBC's Great British Class Survey Experiment'. Sociology. SAGE Journals. Available from: <http://soc.sagepub.com/content/early/2013/03/12/0038038513481128.full.pdf+html> [Accessed 18 June 2013].

Purcell, V. (1948). The Chinese in Malaya. Oxford University Press: London.

Sim, Rita (2011). Unmistakably Chinese, Genuinely Malaysian. Salt Media Publications: Kuala Lumpur.

Tan Chee-Beng (2007). Chinese Overseas: Comparative Cultural Issues. Hong Kong University Press: Hong Kong. 